\title{
Residência Integrada Multiprofissional em Saúde e a pandemia COVID- 19: um relato de experiência
}

\author{
Multiprofessional Integrated Residence in Health and the COVID-19 pandemic: an \\ experience report
}

\begin{abstract}
Residencia Integrada Multiprofesional en Salud y la pandemia COVID-19: un informe de experiencia
\end{abstract}

Juliana Florentino de Lucena1*, Jakeline Gonçalves Bonifácio Sena.

\section{RESUMO}

Objetivo: Refletir sobre o processo de formação em serviço proporcionado pela Residência Integrada Multiprofissional em Saúde, e suas contradições, no contexto da pandemia. Relato de experiência: Trata-se de um relato de experiência, vivenciado nos tempos de pandemia da COVID-19, dentro de um hospital universitário, na Residência Integrada Multiprofissional em Saúde, na área de serviço social. Este estudo refere-se a uma pesquisa exploratória, desenhado dentro do método histórico dialético, que enfatiza a dimensão histórica dos processos sociais diante das observações cotidianas. Nesse contexto de pandemia, as adversidades para o trabalho do assistente social, inserido em um processo de trabalho hospitalar, ficaram mais evidentes, como a desprofissionalização, colocações de atribuições e competências que não cabem ao assistente social realizar, sendo necessário um posicionamento dessa categoria profissional. Outro eixo discutido é sobre o processo de formação em saúde do residente, e reflexões sobre a ambiguidade do papel do residente como agente desse processo. Considerações finais: Percebe-se que é fundamental a atuação dos residentes, porém respeitando todos os compromissos firmados nesse processo de ensinoaprendizagem.

Palavras-chave: Pandemia, Residência não médica não odontológica, Educação permanente, Serviço social.

\section{ABSTRACT}

Objective: To reflect on the in-service training process provided by the Integrated Multiprofessional Residence in Health, and its contradictions, in the context of the pandemic. Experience report: This is an experience report, lived during the pandemic times of COVID-19, inside a university hospital, in the Integrated Multiprofessional Health Residence, in the social service area. This study refers to an exploratory research, designed within the historical dialectical method, which emphasizes the historical dimension of social processes in the face of everyday observations. In this context of a pandemic, the adversities for the work of the social worker, inserted in a hospital work process, became more evident, such as the deprofessionalization, assignments of positions and competencies that are not up to the social worker to perform, being necessary a positioning of this professional category. Another axis discussed is about the resident's health education process, and reflections on the ambiguity of the resident's role as an agent of this process. Final considerations: It is perceived that the residents' performance is fundamental, but respecting all the commitments made in this teaching-learning process.

Key words: Pandemic, Non-dental residency, Permanent education, Social work.

\section{RESUMEN}

Objetivo: Reflexionar sobre el proceso de formación en servicio que brinda la Residencia Multiprofesional Integrada en Salud, y sus contradicciones, en el contexto de la pandemia. Informe de experiencia: Se trata de un relato de experiencia vivida durante la época pandémica del COVID-19, en el interior de un hospital universitario, en la Residencia de Salud Multiprofesional Integrada, en el área de servicios sociales. Este estudio se refiere a una investigación exploratoria, diseñada dentro del método dialéctico histórico, que enfatiza la dimensión histórica de los procesos sociales frente a las observaciones cotidianas. En este contexto de pandemia, se hicieron más evidentes las adversidades para el trabajo de la trabajadora social, insertada en un proceso laboral hospitalario, como la desprofesionalización, asignaciones de encargos y

1 Universidade Federal da Bahia (UFBA), Salvador - BA. *E-mail: asjuliana.Iucena@gmail.com 
competencias que no le corresponde realizar a la trabajadora social, requiriendo un posicionamiento de esta categoría profesional. Otro eje discutido es sobre el proceso de educación en salud del residente y reflexiones sobre la ambigüedad del rol del residente como agente de este proceso. Consideraciones finales: Se percibe que el desempeño de los residentes es fundamental, pero respetando todos los compromisos adquiridos en este proceso de enseñanza-aprendizaje.

Palabras clave: Pandemia, Residencia no dental no dental, Educación permanente, Trabajo social.

\section{INTRODUÇÃO}

Em março de 2020, a Organização Mundial de Saúde (OMS) declarou situação de pandemia diante da rápida propagação da doença causada pelo coronavírus, denominado Severe Acute Respiratory SyndromeCorona Virus-2 SARS-CoV-2, COVID-19 (BASILE C, et al., 2020; LU R, et al., 2020).O contexto da pandemia afeta de várias maneiras, e mundialmente, a sociedade. No Brasil, o enfrentamento vem sendo, majoritariamente, ofertado pelo Sistema Único de Saúde (SUS), que institui a política de saúde como direito de todos e dever do Estado (OMS, 2020).

A pandemia da COVID-19 desvela a realidade que já conhecíamos enquanto profissionais do serviço social. Nesse contexto, estão presentes: o obscurantismo, o conservadorismo, a precariedade escancarada das condições de vida e o trabalho da classe trabalhadora, o oportunismo burguês exacerbado e a negação de direitos sociais.

O (des)governo federal utiliza-se de um projeto ultraliberal conservador, que na pandemia evidencia ainda mais as desigualdades sociais, atingindo, principalmente grupos sociais que já são vulnerabilizados pela sociedade burguesa, como por exemplo, o povo negro, mulheres pretas e pobres, e a comunidade de lésbicas, gays, bissexuais, travestis, transexuais, transgêneros, queers, intersex, agêneros, assexuados e mais (LGBTQIA+) e a população periférica (YAZBEK MC, et al., 2020).

O autor, Mbemb A (2016), em seus estudos, apresenta o conceito de necropolítica, que adota a política de morte como modelo de governar o país, o qual nos serve como elemento para análise no cenário que estamos vivenciando com a pandemia da COVID-19.

As expressões da "questão social" nos tempos presentes (como por exemplo, a pobreza, a precariedade das condições de habitação, a falta de água e saneamento básico para milhões de brasileiros, o aumento da violência doméstica, a intensificação da precarização do trabalho), vão além dos condicionantes biológicos, e, por isso, é equivocado associá-las apenas à pandemia, causada pelo novo coronavírus, sem a devida relação com as crises política e econômica, além da sanitária, que já estavam em andamento.

Essas expressões dispõem de uma dimensão estrutural, enraizada na produção social contraposta à apropriação privada do trabalho, a "questão social" atinge visceralmente a vida dos sujeitos numa luta aberta e surda pela cidadania, no embate pelo respeito aos direitos civis, sociais e políticos e aos direitos humanos (IAMAMOTO MV, 2008 apud IANNI O, 1992).

De acordo com o Código de Ética do Assistente Social, é dever do profissional: participar de programas de socorro à população em situação de calamidade pública, no atendimento e defesa de seus interesses e necessidades (CFESS, 2012). Esses trabalhadores são historicamente reconhecidos como profissionais da saúde e, dessa forma, compuseram a linha de frente no combate a essa pandemia, ou seja, assistente social sempre esteve na linha de frente, atuando no enfrentamento das expressões da "questão social", e não seria diferente nesse momento de pandemia.

A partir dessa realidade apresentada, destaca-se natureza da Residência Integrada Multiprofissional em Saúde, que, conforme a Lei oㅜ 11.129 de 30 de Junho de 2005, é definida como modalidade de ensino de pós-graduação lato sensu, um programa de cooperação intersetorial para favorecer a inserção qualificada dos jovens profissionais da saúde no mercado de trabalho e desenvolvida em regime de dedicação exclusiva sendo realizada sob supervisão docente-assistencial (BRASIL, 2005).

Neste sentido, reitera-se que além das profissionais assistentes sociais, as assistentes sociais residentes também atuam no cenário de pandemia da COVID-19, por isso, este artigo suscita questões, tais como: as 
mudanças na organização do trabalho do serviço social, na sua inserção no processo de trabalho institucional, a significação do real papel do residente - estudante ou trabalhador? - e os desafios encontrados nesse contexto contemporâneo.

O estudo ora apresentado objetiva propiciar reflexões sobre o processo de formação em serviço proporcionado pela Residência Integrada Multiprofissional em Saúde, e suas contradições, no contexto da pandemia. Sua relevância está na possibilidade de contribuir para a reflexão acerca do trabalho do assistente social e dos processos de trabalho nos quais se inserem, além de (re)pensar estratégias de enfrentamento e construção às expressões da "questão social", considerando o contexto da pandemia da COVID-19.

\section{RELATO DE EXPERIÊNCIA}

As inquietações deste estudo foram refletidas dentro do Programa de Residência Integrada Multiprofissional em Saúde, na área de serviço social, em um hospital universitário, na cidade de Salvador BA. As pesquisadoras são assistentes sociais, integrantes da Residência Multiprofissional de Saúde - RMS, agentes instituintes desse processo de formação - tutora e residente, área de concentração Saúde da Criança, desde o ano de 2019.

Ponderando-se os aspectos principais, resultantes desta vivência nos tempos de pandemia, e dialogando com as referências teóricas pertinentes, percebe-se, enquanto pesquisadoras acadêmicas, a importância de refletir sobre esse momento histórico para a categoria profissional junto ao "inimigo invisível". Este cenário proporcionou uma maturação no processo de aprendizagem mesmo diante de todos os desafios que serão apontados, dessa forma, o acúmulo de conhecimento do profissional, assistente social, permite nesse momento de pandemia contribuir com as lutas pela defesa de direitos sociais, já que as expressões da "questão social" continuam se materializando de diversas formas no atual contexto.

A Residência Integrada Multiprofissional em Saúde nasceu de forma articulada e apoiada pelos Ministérios da Educação (MEC) e da Saúde (MS). Os princípios orientadores do Programa de Residência Integrada Multiprofissional em Saúde são: concepção ampliada de saúde, que respeite a diversidade e considere o sujeito inserido num ambiente social, político e cultural; integração ensino, serviço e comunidade; articulação ensino, serviço e gestão; formação integral, interdisciplinar e multiprofissional; e estímulo à formação e atuação em equipe.

No que se refere ao regime de funcionamento da Residência Integrada Multiprofissional em Saúde são dois anos de duração, e carga horária total de 5.760 horas entre teoria e prática. O residente cumpre carga horária semanal de 60 horas, incluindo plantões diante escala do serviço. A carga horária semanal, 48 horas são destinadas para as atividades de educação em serviço e 12 horas para as atividades acadêmicas, incluindo atividades presenciais e estudo individual.

O Programa de Residência Integrada Multiprofissional em Saúde, o qual estamos inseridas, proporciona aprendizagem por meio da articulação entre teoria e da prática profissional, possibilitando ao residente um aprendizado singular no âmbito da saúde. Os residentes são profissionais que trabalham no SUS se especializando em diversas áreas de concentração como, por exemplo: saúde do adulto, saúde da criança e saúde mental.

Nessa relação, da teoria e prática profissional, não podemos desconsiderar o aprendizado e amadurecimento que é proporcionado diante da atuação prática do residente, em específico na pandemia e seus múltiplos desafios. Dessa forma, para não comprometer esse aprendizado, cabe a todos envolvidos nesse contexto como os tutores, preceptores e demais profissionais que estão inseridos nesse processo compreenderem que este espaço de aperfeiçoamento profissional, na perspectiva da formação continuada em serviço, é articulado a um projeto de ensino-aprendizagem e que se constitui como eixo de formação profissional.

Diante do exposto, surgem algumas inquietações que nos levam as seguintes reflexões: se atuamos em locais insalubres por que não recebemos insalubridade como os trabalhadores da saúde? Somos uma peça fundamental como mão de obra para SUS? Por que somente na pandemia passamos a ter direito a uma 
bonificação? Quais os motivos dos estudantes das universidades públicas serem afastados, e nós residentes não conseguimos afastamento, mesmo fazendo parte dessa categoria? E persiste a indagação: sou trabalhador ou estudante? Salienta-se que essas indagações são consideradas fundamentais para refletir esta dúbia inserção dos residentes nos Hospitais Universitários, levando a pensar que somos estudantes, porém estamos em processo de formação que deve ser acompanhado pelos tutores e preceptores na nossa rotina cotidiana, embora, também sejamos trabalhadores nos espaços sócio-ocupacionais nos quais atuamos.

Assim, nesse cenário complexo e diante das exposições realizadas anteriormente, elencou-se novos desafios, e os que foram acentuados na pandemia, tais como: suspensão do calendário acadêmico como medida de proteção diante da pandemia, o que impactou na oferta da carga horária teórica e prejudicou a relação teórico-prática; medo de atuar sem experiência profissional, já que uma grande parte dos residentes se insere no Programa nessas condições; adaptação a novos fluxos de trabalho para atender as demandas da instituição e dos usuários; falta de investimento em tecnologia da informação que seria uma ferramenta importante para auxiliar nos processos de trabalho; reafirmação constante sobre competências e atribuições do assistente social diante de requisições equivocadas; escassez de Equipamentos de Proteção Individual (EPI) e treinamentos específicos voltados à COVID-19; adoecimento físico e psíquico dos residentes multiprofissionais devido à extensa carga horária no contexto da pandemia; sobrecarga de trabalho dos profissionais que são preceptores, impedindo por vezes, que estes se dediquem à formação continuada e aperfeiçoamento profissional; transferência ao setor privado das tecnologias construídas no âmbito da residência, uma vez que o SUS não absorve esta força de trabalho.

\section{DISCUSSÃO}

Inicialmente, faz-se necessário resgatar algumas ponderações no que tange o conceito de saúde, e especificar como funciona o Programa de Residência Integrada Multiprofissional em Saúde, pontos estes de extrema relevância. Conforme especifica o Conselho Nacional de Saúde, Resolução no 287 de 08 de outubro de 1998, a 8 ${ }^{\text {a }}$ Conferência Nacional de Saúde ampliou a compreensão da relação saúde/doença como decorrência das condições de vida e trabalho, bem como do acesso igualitário de todos aos serviços de promoção, proteção e recuperação da saúde, colocando como uma das questões fundamentais a integralidade da atenção à saúde e a participação social (BRASIL, 1998).

Nesta perspectiva, que resulta das lutas sociais históricas em torno da saúde como direito, o serviço social, enquanto especialização do trabalho foi uma das categorias profissionais que passou a compor as equipes de saúde compreendendo o sujeito para além das suas questões biológicas, contribuindo para a consolidação do modelo de saúde orientado por uma visão democrática, participativa e com centralidade no usuário, buscando romper com o modelo hegemônico de saúde.

Nascimento DD e Oliveira MA (2010), pontuam que o Sistema Único de Saúde veio ganhando espaço e o Ministério da Saúde percebeu a necessidade de buscar caminhos para orientar a formação dos profissionais do SUS, por esta razão já se pensavam em estratégias para a formação em saúde desde a década de 1980. Com essa necessidade, e resultado de uma luta coletiva da sociedade brasileira, institui-se no ano de 2004, a Política Nacional de Educação Permanente em Saúde (PNEPS), que representa um marco para a formação e trabalho em saúde no país. A PNEPS é uma proposta de ensino-aprendizagem, e essa estratégia pedagógica é desenvolvida dentro do cotidiano institucional das organizações do SUS.

A Educação Permanente em Saúde (EPS) apresenta uma perspectiva de conhecimento dentro do próprio processo de trabalho em saúde e se configura como uma proposta de aprendizagem no trabalho, onde o aprender e o ensinar se incorporam ao cotidiano das organizações, consolidando o SUS. A EPS formulada dentro de um contexto de aprendizagem significativa busca transformar aquela realidade vivenciada por meio de reflexões críticas, interligando veementemente o aprender e ensinar dentro do mundo da formação e 0 mundo do trabalho (BRASIL. MINISTÉRIO DA SAÚDE. 2018).

Consoante a essa discussão, a Residência Multiprofissional em Saúde (RMS) pode ser compreendida como um dispositivo de educação permanente que promove uma aproximação dos profissionais de saúde 
junto à população usuária assistida pelo SUS, possibilitando conhecer mais de perto a realidade vivenciada e dessa forma uma atuação profissional diferenciada, pois esse formato de educação dialoga entre construções de saberes diferentes, possibilitando a efetivação do cuidado dentro da perspectiva do que preconiza a Reforma Sanitária brasileira e os princípios do SUS (SILVA CT, et al., 2016)

Com a pandemia, o modelo de organização e regime de funcionamento da Residência Multiprofissional em Saúde (RMS) sofreram ajustes e o setor de serviço social reorganizou os fluxos de trabalho visando à segurança dos usuários, trabalhadores e residentes. Levou-se em consideração para a devida reorganização as orientações da OMS, do Conselho Federal de Serviço Social (CFESS), Conselho Regional de Serviço Social (CRESS) e normas orientadoras internas do referido hospital.

A pandemia não alterou a função social da profissão, embora tenha modificado os fluxos de trabalho, e como parte de um trabalhador coletivo, o assistente social tem uma contribuição fundamental nos diferentes serviços de saúde. O que se altera no serviço social é a forma como se dará o trabalho, sem, contudo, alterar nossas atribuições privativas e competências profissionais (MATOS MC, 2020). Apesar destas alterações, especificamente no tocante aos protocolos de segurança sanitária que passaram a ser exigidos, a exemplo dos teleatendimentos, seguimos reiterando nosso compromisso com a população usuária do SUS.

Para o enfrentamento à pandemia do coronavírus, o Ministério da Saúde concedeu bonificação de $20 \%$ sobre o valor da bolsa paga aos residentes como reconhecimento pelo trabalho prestado e incentivo ao enfrentamento da pandemia, formalizado na Portaria № 580, de 27 de março de 2020. A iniciativa faz parte da ação estratégica "O Brasil Conta Comigo", que tem como proposta ampliar a força de trabalho no SUS, garantir a melhor assistência à população brasileira e apoiar os profissionais que atuam na linha de frente (BRASIL, 2020).

Assim, um ponto relevante para ponderação diz respeito à extensa carga horária de 60 horas semanais, que intensifica o trabalho do residente, proposta no Programa de Residência Integrada Multiprofissional em Saúde. Essa proposta precariza o processo ensino-aprendizagem, além disto, vai de encontro à luta da nossa categoria de assistentes sociais que com a Lei oㅜ 12.317, de 27 de agosto de 2010, estabeleceu a jornada de trabalho de 30 horas semanais para assistentes sociais (BRASIL, 2010).

Os desafios já fazem parte do cotidiano profissional do assistente social, que precisa realizar um movimento contínuo de leitura e apreensão da realidade, num processo de construção de respostas mediadas pelas demandas sociais e institucionais, além das condições e relações de trabalho.

Cabe destacar que com a pandemia houve uma intensificação destes desafios, e que no cotidiano do serviço social, torna-se imprescindível um profissional com competência crítica para enfrentamento dos mesmos, sem cair nas armadilhas do tecnicismo, de uma "prática" que abre mão da reflexão. Diante desses desafios, o (a) Assistente Social deve utilizar-se da dimensão investigativa do trabalho profissional para propor melhorias nas políticas sociais e no seu cotidiano de trabalho (MATOS MC, 2020).

Com relação a essa discussão, lamamoto MV (1998) pontua que é preciso desenvolver repostas criativas para atender aquele usuário que chega com demandas emergentes, compreendendo-o enquanto cidadão de direito, e que estes profissionais sejam capazes de não apenas executar, mas saibam construir propostas democráticas dentro do seu cotidiano profissional.

Dessa forma, trazendo para o atual cenário que estamos vivenciando, trata-se de novas possibilidades de atuação, do ser criativo e se requalificar para atender dentro de novos fluxos que visam à segurança do usuário e profissional, garantido o direito dos usuários sem cair no imediatismo diante das intervenções efetivadas.

Neste sentido, conclui-se que é fundamental a atuação dos residentes no atual contexto, já que este é um profissional que desenvolve seu trabalho e formação acadêmica numa linha tênue, que, contudo, deve ser preservada respeitando-se os compromissos firmados nesse processo de ensino-aprendizagem, garantindose os princípios da formação em serviço, no Programa de Residência Integrada Multiprofissional em Saúde para que não se perca estes princípios no decorrer do percurso, diante de um contexto atípico, como o da pandemia da COVID-19. 


\section{REFERÊNCIAS}

1. BRASIL, 2005. Lei 11.129 de 30 de junho 2005.

2. BRASIL, 2010. Lei no 12.317 , de 26 de agosto de 2010.

3. BRASIL, 1998. Resolução n- 287 de 08 de outubro de 1998.

4. BRASIL, 2020. Portaria no 580, de 27 de março de 2020.

5. BRASIL. Ministério da Saúde. Secretaria de Gestão do Trabalho e da Educação na Saúde. Departamento de Gestão da Educação na Saúde. Política Nacional de Educação Permanente em Saúde: o que se tem produzido para o seu fortalecimento? / Ministério da Saúde, Secretaria de Gestão do Trabalho e da Educação na Saúde, Departamento de Gestão da Educação na Saúde - 1. ed. rev. - Brasília : Ministério da Saúde, 2018.

6. BORTOLETTO GE. LGBTQIA+: identidade e alteridade na comunidade. São Paulo, 2019.

7. CFESS. Código de Ética do Assistente Social e Lei 8.662/93 (10ª edição, revista e atualizada). Brasília: CFESS, 2012.

8. GUERRA Y. A instrumentalidade do Serviço Social. 10ª Ed. São Paulo: Cortez, 2014.

9. IAMAMOTO MV. O Serviço Social na contemporaneidade: trabalho e formação profissional. São Paulo: Cortez, 1998.

10. IANNI O. A Questão Social. In: A ideia do Brasil moderno. São Paulo: Brasiliense, 1992, 87-109.

11. MATOS MC. A pandemia do coronavírus (COVID-19) e o trabalho de assistentes sociais na saúde, 2020

12. MATOS MC. (Des) informação nos serviços de saúde em tempos da pandemia da Covid-19: uma questão ética e uma requisição enviesada ao trabalho de Assistentes Sociais, 2020.

13. MBEMBE A. Necropolítica. Revista Artes e Ensaios, 2016; (2): 123-151.

14. NASCIMENTO DD, OLIVEIRA MA. Competências profissionais e o processo de formação na residência multiprofissional em Saúde da Família. Saúde soc., São Paulo, 2010.

15. ORGANIZAÇÃO MUNDIAL DA SAÚDE (OMS). Folha informativa - COVID-19 (doença causada pelo novo coronavírus), 2020.

16. SILVA CT, et al. Residência multiprofissional como espaço intercessor para a educação permanente em saúde. Revista Texto Contexto Enferm, 2016; 25 (1): e2760014.

17. YAZBEK MC, et al. Questão social, trabalho e crise em tempos de pandemia. Revista Serv. Soc. Soc., São Paulo, 2020. 